\title{
Burning high-level TRU waste in fusion fission reactors
}

\author{
Yaosong Shen \\ Institute of Applied Physics and Computational Mathematics, 6 Huayuan Road, \\ 100088, Beijing, China \\ Yaosongshen@hotmail.com
}

Published 1 September 2016

\begin{abstract}
Recently, the concept of actinide burning instead of a once-through fuel cycle for disposing spent nuclear fuel seems to get much more attention. A new method of burning high-level transuranic (TRU) waste combined with Thorium-Uranium (Th-U) fuel in the subcritical reactors driven by external fusion neutron sources is proposed in this paper. The thorium-based TRU fuel burns all of the long-lived actinides via a hard neutron spectrum while outputting power. A one-dimensional model of the reactor concept was built by means of the ONESN_BURN code with new data libraries. The numerical results included actinide radioactivity, biological hazard potential, and much higher burnup rate of high-level transuranic waste. The comparison of the fusion-fission reactor with the thermal reactor shows that the harder neutron spectrum is more efficient than the soft. The Th-U cycle produces less TRU, less radiotoxicity and fewer long-lived actinides. The Th- $U$ cycle provides breeding of ${ }^{233} \mathrm{U}$ with a long operation time ( $>20$ years), hence significantly reducing the reactivity swing while improving safety and burnup.
\end{abstract}

Keywords: Fusion Fission Reactor; High-level Transuranic Waste; Thorium-Uranium Fuel Cycle; Thorium Base TRU Fuel; Actinide Burning.

PACS numbers: 25.70.Jj, 28.52.Av, 28.41.Ak, 28.65.+a.

\section{Introduction}

The world's nuclear electric capacity of nearly 380 gigawatts-electric (GWe) produces spent nuclear fuel roughly amounting to 8000 tonnes of heavy metal (tHM) per year. Among various reactors, the light water reactor (LWR) type is the most widely deployed. A modern LWR of 1 GWe capacity will typically discharge about 20-25 tonnes of irradiated spent fuel per year of operation. The spent fuel is comprised of $93-94 \%$ of the mass of uranium oxide (mostly ${ }^{238} \mathrm{U}$, only $0.8 \%{ }^{235} \mathrm{U}$ ), $\sim 3-5 \%$ fission products, $\sim 1 \%$ plutonium, and $\sim 0.1-0.2 \%$ minor actinides (MA, including neptunium, americium and curium). Although there are a number of fission product radionuclides of high activity $\left({ }^{137} \mathrm{Cs}\right.$ and $\left.{ }^{90} \mathrm{Sr}\right)$ and long half-life $\left({ }^{99} \mathrm{Tc}, 2.1124 \mathrm{E}+5\right.$ years; and ${ }^{129} \mathrm{I}, 1.5711 \mathrm{E}+7$ years $)$ in spent nuclear fuel, actinides and their daughter products account for most of the radiotoxicity of nuclear waste after the first 500 years of disposal, and most of the radiotoxicity of high-level waste (HLW) is from transuranic elements (TRU), especially isotopes of $\mathrm{Pu}$.

This is an Open Access article published by World Scientific Publishing Company. It is distributed under the terms of the Creative Commons Attribution 3.0 (CC-BY) License. Further distribution of this work is permitted, provided the original work is properly cited. 
Traditionally, there are two types of fuel cycles: (1) open, with the direct disposal of spent fuel and (2) closed, with the reprocessing of spent fuel to recover and use fissile and fertile fuel that remains. Traditional closed fuel cycles recycle uranium and plutonium, but MAs are treated as waste. However, recently proposed technology termed as "actinide burning" irradiates actinides chemically separated from spent fuel to convert them to short-lived radionuclides or non-radioactive elements. With actinide burning, all of the actinides are to be destroyed.

A fuel cycle that burns actinides is significantly different from a traditional fuel cycle. It is these differences that lead to consideration of different reactors and fuel cycles for this mission. For example, Hyland et al. proposed MA burning in LWR or CANDU; ;,3 Forsberg et al. proposed molten salt reactors (MSRs, liquid-fueled reactors) can be used for burning actinides; ${ }^{4}$ Hejzlar et al. proposed actinide burning in a leadbismuth-cooled critical fast reactor (LFR); ${ }^{5}$ and Sandia National Laboratories designed a Z-pinch fusion driver for the transmutation of TRU. ${ }^{6}$

In this paper, we propose a new concept of actinide burning with a thorium-uranium (Th-U) cycle with an external fusion neutron source (14.1 MeV). Such a fusion-fission reactor (FFR) can be driven by various external neutron sources, such as ITER, Z-Pinch, ICF or even ADS. A FFR has a neutron spectrum harder than that of the other reactors (fast or thermal); such a hard neutron spectrum is generally more effective in the fission of TRU. The advantages of the Th-U cycle include: (1) less TRU, less radiotoxicity and fewer long-lived actinides; (2) only one stable isotope of thorium $\left({ }^{232} \mathrm{Th}\right)$; (3) breeding of ${ }^{233} \mathrm{U}$ within a long operation time ( $>20$ years) significantly reducing the reactivity swing and improving safety; (4) high achievable burnup; and (5) lower cost of thorium as compared to alternatives. The coolant of the FFR is liquid lead $(\mathrm{Pb})$, and the structural material fractions are austenitic stainless steel SS316, the same as that of the LFR.

The calculations in this paper are performed using the One-dimension Sn neutronPhoton Transport and Burn-up calculation code (OneSn_Burn) developed at the Institute of Applied Physics and Computational Mathematics (IAPCM). OneSn_Burn has several data libraries: (1) 172 group of neutron cross sections for 501 nuclei; (2) 32 group of photon cross sections for all 1-100 elements; (3) 3468 isotopes of decay library; (4) 33 actinides fission product yields library; and (5) miscellaneous data library for Biological Hazard Potential (BHP) calculation and material neutron and photon radiation damage (DPA) calculation.

\section{Calculation and Analysis}

Table 1 shows the TRU properties of regular LWR spent fuel; the atomic fraction of TRU is taken from the Ref. 6. Here, Pu is more than $80 \%$, Am is about $11 \%, \mathrm{~Np}$ is about $7 \%$ and $\mathrm{Cm}$ is less than $1 \%$. First, we calculate the effectiveness of MA burning by different neutron spectra. Figure 1 shows neutron spectra for a typical pressurized water reactor (PWR) and for the FFR driven by a $14.1 \mathrm{MeV}$ external fusion neutron source analyzed in the present work. The PWR spectrum reaches a peak at $0.01-0.1 \mathrm{eV}$, while the FFR spectrum appears to be more complicated with several peaks at $14.1 \mathrm{MeV}$, 
fission energy zone and $10-100 \mathrm{eV}$. The FFR spectrum is similar to that of a critical fast reactor LFR except at $14.1 \mathrm{MeV}$.

Table 1. TRU properties of LWR spent fuel. The atomic fractions are taken from Ref. 6.

\begin{tabular}{llll}
\hline Actinide Isotope & \multicolumn{2}{l}{ Atomic fraction Half-life $(\mathrm{y})$} & Decay mode \\
\hline${ }^{236} \mathrm{~Np}$ & $7.3147 \mathrm{E}-08$ & $1.5310 \mathrm{E}+05$ & $\beta$ \\
${ }^{237} \mathrm{~Np}$ & $7.3435 \mathrm{E}-02$ & $2.1454 \mathrm{E}+06$ & $\alpha$ \\
${ }^{239} \mathrm{~Np}$ & $1.7966 \mathrm{E}-08$ & $6.4547 \mathrm{E}-03$ & $\beta$ \\
${ }^{238} \mathrm{Pu}$ & $2.6630 \mathrm{E}-02$ & $8.7760 \mathrm{E}+01$ & $\alpha$ \\
${ }^{239} \mathrm{Pu}$ & $4.5452 \mathrm{E}-01$ & $2.4127 \mathrm{E}+04$ & $\alpha$ \\
${ }^{240} \mathrm{Pu}$ & $2.6288 \mathrm{E}-01$ & $6.5656 \mathrm{E}+03$ & $\alpha$ \\
${ }^{241} \mathrm{Pu}$ & $9.2059 \mathrm{E}-03$ & $1.4299 \mathrm{E}+01$ & $\beta$ \\
${ }^{242} \mathrm{Pu}$ & $5.7352 \mathrm{E}-02$ & $3.7376 \mathrm{E}+05$ & $\alpha$ \\
${ }^{244} \mathrm{Pu}$ & $1.1055 \mathrm{E}-05$ & $8.1156 \mathrm{E}+07$ & $\alpha$ \\
${ }^{241} \mathrm{Am}$ & $9.2075 \mathrm{E}-02$ & $4.3290 \mathrm{E}+02$ & $\alpha$ \\
${ }^{242} \mathrm{Am}$ & $1.9452 \mathrm{E}-09$ & $1.8287 \mathrm{E}-03$ & $\beta$ \\
${ }^{242 m} \mathrm{Am}$ & $1.6305 \mathrm{E}-04$ & $1.4109 \mathrm{E}+02$ & $\gamma$ \\
${ }^{243} \mathrm{Am}$ & $2.0530 \mathrm{E}-02$ & $7.3749 \mathrm{E}+03$ & $\alpha$ \\
${ }^{242} \mathrm{Cm}$ & $3.9434 \mathrm{E}-07$ & $4.4641 \mathrm{E}-01$ & $\alpha$ \\
${ }^{243} \mathrm{Cm}$ & $2.7573 \mathrm{E}-05$ & $2.9120 \mathrm{E}+01$ & $\alpha$ \\
${ }^{244} \mathrm{Cm}$ & $2.1100 \mathrm{E}-03$ & $1.8123 \mathrm{E}+01$ & $\alpha$ \\
${ }^{245} \mathrm{Cm}$ & $8.6423 \mathrm{E}-04$ & $8.5057 \mathrm{E}+03$ & $\alpha$ \\
${ }^{246} \mathrm{Cm}$ & $1.9336 \mathrm{E}-04$ & $4.7633 \mathrm{E}+03$ & $\alpha$ \\
${ }^{247} \mathrm{Cm}$ & $3.7225 \mathrm{E}-06$ & $1.5610 \mathrm{E}+07$ & $\alpha$ \\
${ }^{248} \mathrm{Cm}$ & $4.2804 \mathrm{E}-07$ & $3.4824 \mathrm{E}+05$ & $\alpha$ \\
\hline
\end{tabular}

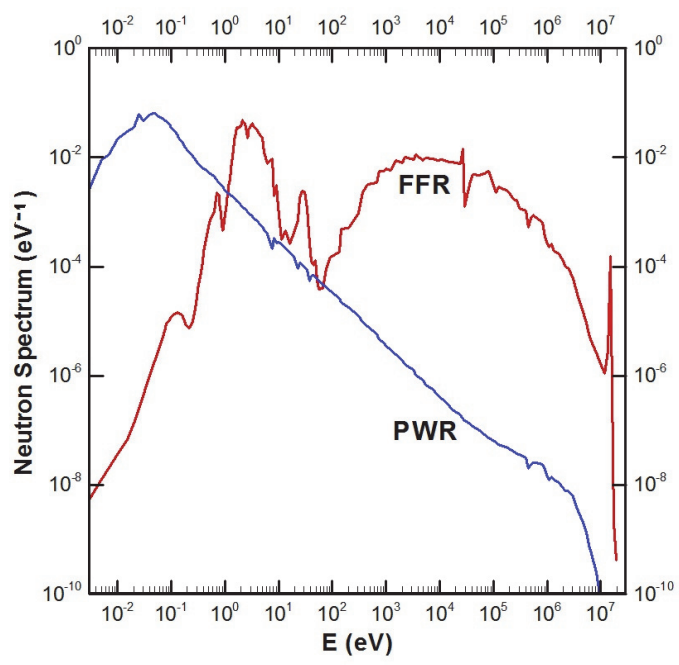

Fig. 1. Comparison of neutron spectra: the blue line is a PWR spectrum and the red line is the FFR spectrum. All calculation is done by OneSn_Burn code. 
Figure 2 shows how the actinide radioactivity of TRU fuel changes with different neutron spectra (PWR, FFR, and single energy 14.1 MeV) with a constant neutron flux $\left(1.0 \mathrm{E}+14 \mathrm{n} / \mathrm{s} / \mathrm{cm}^{2}\right.$, regular neutron flux in the fuel zone of the thermal reactor). Under an 18-month operation (PWR typical operation time) at constant neutron flux, the radioactivity shows different changes for all considered cases. The original TRU result (natural decay of TRU fuel) is given for comparison. At the beginning of irradiation, the radioactivity increases rapidly because of production of many short-lived actinides from neutron reactions, such as $(n, \gamma),(n, x n)$ and $(n, p / t / \alpha)$. The harder the neutron spectrum is, the fewer short-lived actinides are produced. During the 18 months of burning, the radioactivity is constant, and changes are very small. After shutdown, the radioactivity quickly decreases due to the decay of short-lived actinides to stable nuclides. It is obvious that the FFR and single energy 14.1 MeV lines decrease below the original TRU line after several years of cooling, but the PWR line cannot drop below the original TRU line until after 500 years of cooling. The reason is that the PWR spectrum is very soft and has a larger $(\mathrm{n}, \gamma)$ cross section of ${ }^{239} \mathrm{Pu}$ and ${ }^{240} \mathrm{Pu}$, resulting in generation of ${ }^{241} \mathrm{Pu}$ (14.3 years half-life, see Table 1). The number densities of ${ }^{241} \mathrm{Pu}$ after an 18 -month operation of a PWR, FFR and single energy $14.1 \mathrm{MeV}$ spectrum are $4.0682 \mathrm{E}+21 / \mathrm{cm}^{3}$, $2.3570 \mathrm{E}+20 / \mathrm{cm}^{3}$ and $2.2966 \mathrm{E}+20 / \mathrm{cm}^{3}$, respectively. The major disadvantage of actinide burning at a thermal reactor is that it needs a long cooling time ( $>100$ years) after the reactor shutdown because of ${ }^{241} \mathrm{Pu}$.

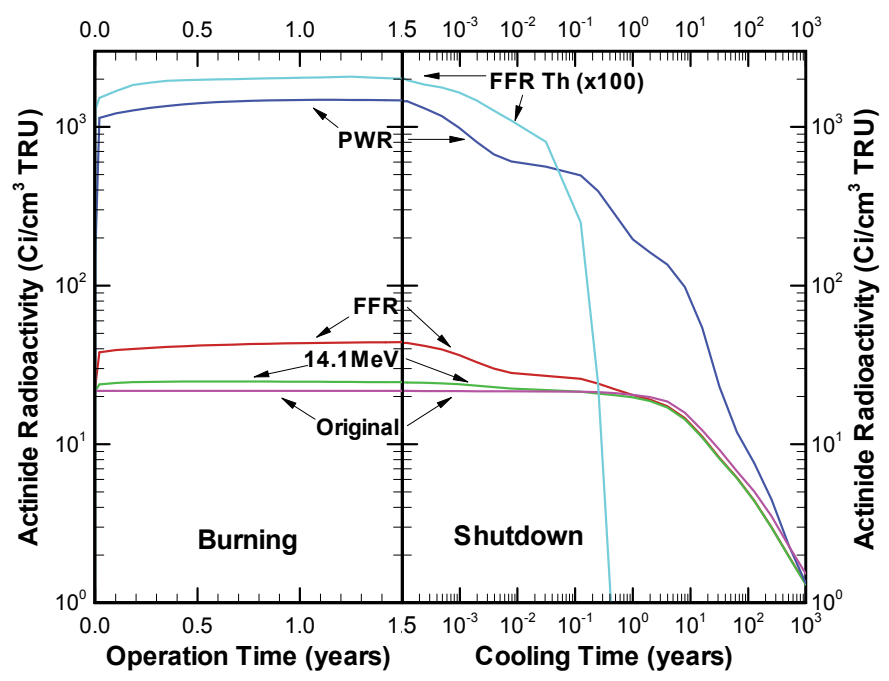

Fig. 2. Actinide radioactivity of TRU fuel during burning and shutdown. Left part of the figure corresponds to burning with a constant neutron flux $\left(1.0 \mathrm{E}+14 \mathrm{n} / \mathrm{s} / \mathrm{cm}^{2}\right)$ for 1.5 years, and then shutdown (no neutron flux) for cooling (right part of the figure). The blue, red and green lines denote the results calculated by different neutron spectra of PWR, FFR, and single energy $14.1 \mathrm{MeV}$, respectively. The purple line is the original value line with un-irradiated TRU (no neutron flux). The cyan line, which is multiplied by a factor of 100 , is ${ }^{232} \mathrm{Th}$ resulting from the FFR spectrum (the original value of ${ }^{232} \mathrm{Th}$ is almost zero). 
The cyan line in Fig. 2 shows the actinide radioactivity of thorium $\left({ }^{232} \mathrm{Th}\right)$ in the FFR spectrum. ${ }^{232} \mathrm{Th}$ is a stable element and results in no radioactivity generation if it is not subjected to neutron irradiation. After one $(\mathrm{n}, \gamma)$ reaction and two $\beta$-decays, ${ }^{232} \mathrm{Th}$ decays to the fissile element ${ }^{233} \mathrm{U}$, similar to ${ }^{235} \mathrm{U}$. This fuel cycle is called the Th-U cycle. The actinide radioactivity of $\mathrm{Th}-\mathrm{U}$ is much less than the regular $\mathrm{U}-\mathrm{Pu}$ cycle in a thermal reactor. As shown in the left part of Fig. 2, the actinide radioactivity of ${ }^{232} \mathrm{Th}$ is closer to that of TRU fuel because of the short-lived actinide at the beginning of the burning; but after reactor shutdown, the actinide radioactivity of ${ }^{232} \mathrm{Th}$ deceases very rapidly during $1-$ 6 months compared to TRU fuel. The Th-U cycle produces less TRU, and the long-term actinide radioactivity mainly comes from ${ }^{231} \mathrm{~Pa}$ (half-life $4.73 \mathrm{E}+04$ years) and its daughter nuclide. In fact, the actinide radioactivity of ${ }^{232} \mathrm{Th}$ is only about $0.01-0.1 \%$ of the TRU at the same mass after six months of cooling. So we ignore the actinide radioactivity of ${ }^{232} \mathrm{Th}$ in the following calculation.

We propose a concept of TRU burning with the Th-U cycle by the FFR. The TRU fuel is placed closer to the $14.1 \mathrm{MeV}$ fusion source (core), and the thorium fuel is surrounded by liquid lead coolant. The FFR neutron flux will reach $1.0-3.0 \mathrm{E}+15 \mathrm{n} / \mathrm{s} / \mathrm{cm}^{2}$ with a $200 \mathrm{MW} 14.1 \mathrm{MeV}$ fusion neutron source. During the FFR operation, the fission reactivity of TRU will decrease, and the fission reactivity of the Th-U cycle (from ${ }^{233} \mathrm{U}$ ) will increase slowly to compensate and keep the total power of the reactor $(3000 \mathrm{MWe}$ heat) balanced for more than 30 years. In the calculation, we adjust the source strength to keep the total power of the reactor at $3000 \mathrm{MW}_{\mathrm{e}}$ heat with about ten tons of TRU fuel.

Figures 3-5 show the numerical results of TRU burning by the FFR. It is clear that the different TRU elements contribute to the different cooling times. Figure 3 shows the actinide radioactivity versus cooling time. Before 50 years, the primary radionuclides of TRU will be ${ }^{238} \mathrm{Pu},{ }^{244} \mathrm{Cm}$ and ${ }^{241} \mathrm{Pu}$, and the contribution of ${ }^{241} \mathrm{Am}$ decreases obviously after 30 years of burning. ${ }^{244} \mathrm{Cm}$ and ${ }^{241} \mathrm{Pu}$ will completely decay after 100 years. The long-term actinide radioactivity after 100 years has a significant decrease because all of the long-lived TRU elements, such as ${ }^{239} \mathrm{Pu},{ }^{241} \mathrm{Am},{ }^{240} \mathrm{Pu}$ and ${ }^{243} \mathrm{Am}\left({ }^{239} \mathrm{~Np}\right.$ is the daughter nuclide of ${ }^{241} \mathrm{Am}$ with a short half-life of 2.356 days), are more or less reduced. 


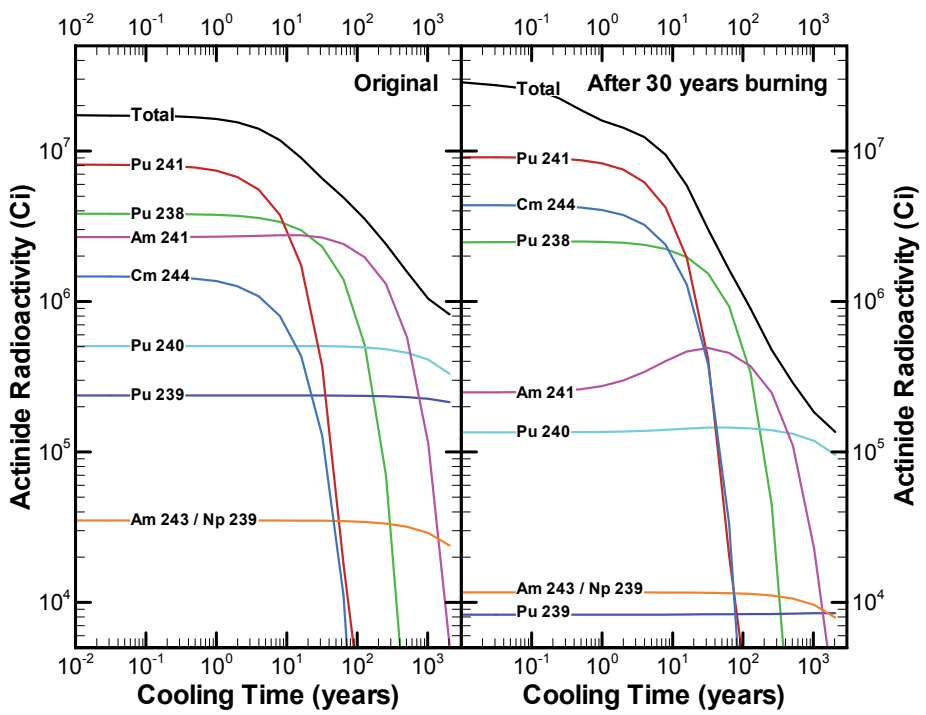

Fig. 3. Actinide radioactivity of TRU fuel vs. cooling time. Left part of the figure is the original TRU fuel, and right part of the figure is TRU fuel after 30 years burning at FFR with constant power of $3000 \mathrm{MW}_{\mathrm{e}}$.

Since the radioactivity shown in Fig. 3 does not include a measure of the radiotoxicity of a radionuclide, a quantity called "biological hazard potential" has been introduced (BHP, in units of $\mathrm{m}^{3}$ of air contaminated by the entire reactor). The metabolism of radionuclides in a reference man has been formulated in models based on which the maximum permissible concentrations (MPC) of radionuclides in air (or water) for occupationally exposed workers have been calculated. The definition of the potential biological hazard (BHP) is given by Eq. (1):

$$
B H P=\sum B H P_{i}=\sum_{i} Q_{i} / M P C_{i},
$$

where $Q_{i}, M P C_{i}$ and $B H P_{i}$ are the $i$ th radionuclide's radioactivity (in units of curie, $\mathrm{Ci}$ ), maximum permissible concentrations (in units of $\mathrm{Ci} / \mathrm{m}^{3}$ ), and biological hazard potential (in units of $\mathrm{m}^{3}$ of air), respectively. Figure 4 shows the BHP of TRU fuel, before 100 years of cooling, where the primary radionuclide of TRU is ${ }^{238} \mathrm{Pu}$; after 500 years, the primary radionuclide of TRU is ${ }^{240} \mathrm{Pu}$ after 30 years of burning. Here the BHP of ${ }^{241} \mathrm{Am}$ and ${ }^{239} \mathrm{Pu}$ decrease significantly, and ${ }^{240} \mathrm{Pu}$ and ${ }^{243} \mathrm{Am}$ decrease a little. Because the actinide elements contribute to more than $90 \%$ of the total long-term BHP, the key to $\mathrm{BHP}$ reduction is decreasing the density of ${ }^{238} \mathrm{Pu}$ and ${ }^{240} \mathrm{Pu}$. 


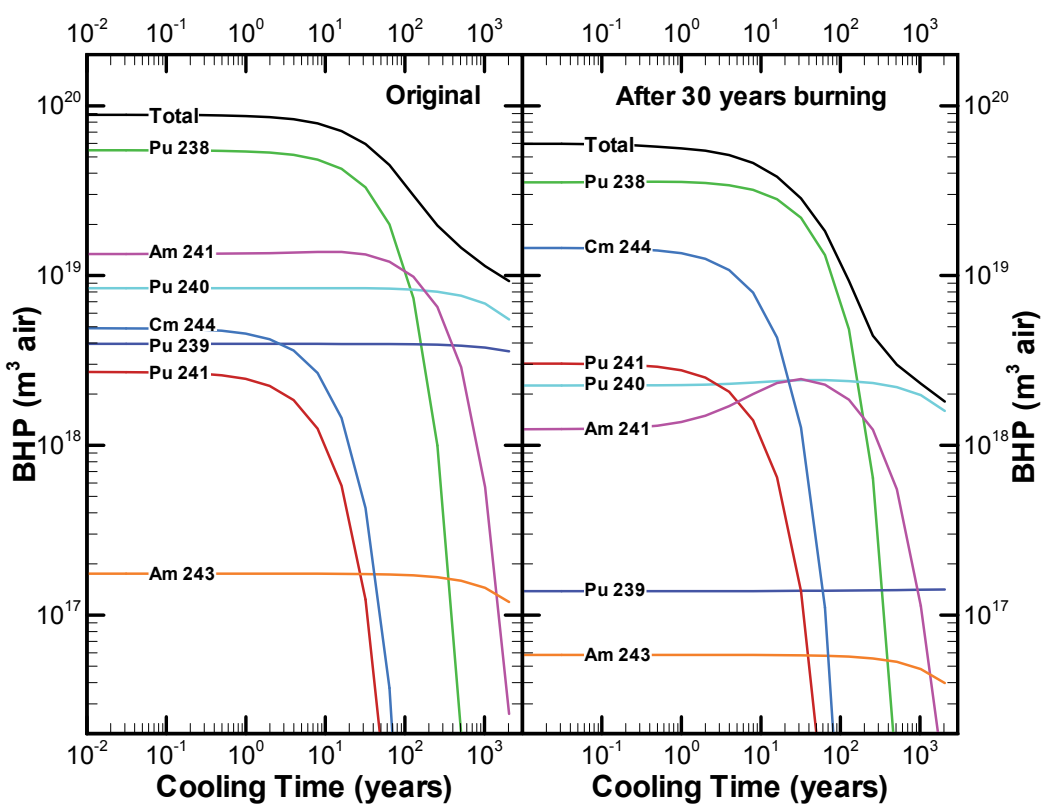

Fig. 4. Same as Fig. 3, but for BHP.

Figure 5 shows that the density of some long-term TRU elements changes during the 30 years of operation. It is clear that ${ }^{239} \mathrm{Pu},{ }^{237} \mathrm{~Np}$ and ${ }^{241} \mathrm{Am}$ drop down quickly, and ${ }^{240} \mathrm{Pu}$ and ${ }^{242} \mathrm{Pu}$ decrease a little slower than ${ }^{241} \mathrm{Am} .{ }^{238} \mathrm{Pu}$ and ${ }^{241} \mathrm{Pu}$ increase in the first 35 years and then decrease slowly, reaching the original level at the end of 30 years. ${ }^{242} \mathrm{Cm}$ increases rapidly in the first two years, then decreases to the original level near 30 years. Only ${ }^{244} \mathrm{Cm}$ has a significant increase at the end of 30 years because ${ }^{241} \mathrm{Am}$ has a $(\mathrm{n}, \gamma)$ reaction to ${ }^{244} \mathrm{Am}$ (14.57 hours half-life), which decays quickly to ${ }^{244} \mathrm{Cm}$. The amounts of density of TRU will decrease to $17 \%$ of the original value after 30 years of burning by the FFR, and the reactor has a capacity of burning about $280 \mathrm{~kg}$ TRU per year and outputting $3000 \mathrm{MW}_{\mathrm{e}}$ of heat. 


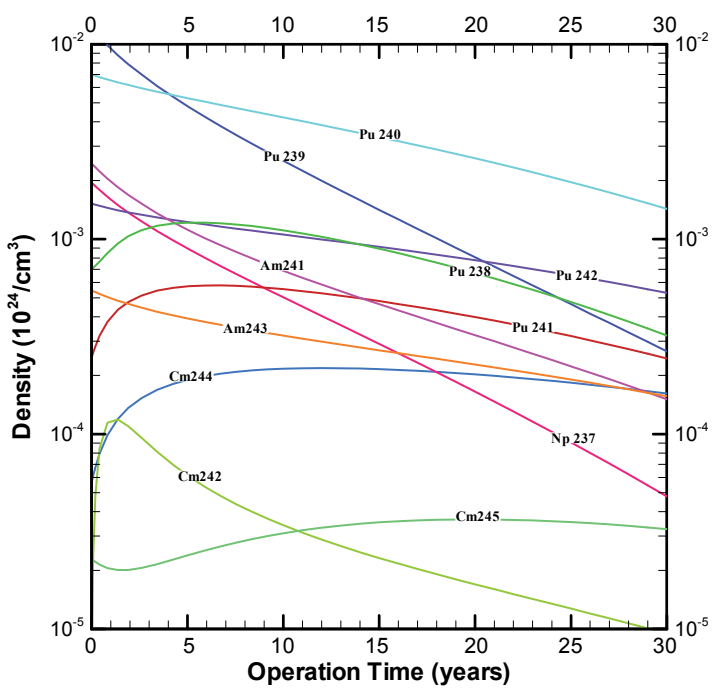

Fig. 5. Density of some long term TRU elements vs. the operation time.

\section{Conclusion}

Above 3-5 Mev, the $(\mathrm{n}, \gamma)$ cross section of most TRU elements is smaller than that of the $(\mathrm{n}, \mathrm{f})(\mathrm{n}, \mathrm{xn})$ and $(\mathrm{n}, \mathrm{p} / \mathrm{t} / \alpha)$ cross sections. Above $0.1 \mathrm{MeV}$, the $(\mathrm{n}, \gamma)$ cross section of most TRU elements is smaller than that of the fission (n,f) cross section. But below $10 \mathrm{eV}$, the $(\mathrm{n}, \gamma)$ reaction is dominant, and it is the only reaction for some TRU elements. The key to actinide burning is TRU fission, so the essential condition is the presence of a hard neutron spectrum. The hard spectrum is produced by fusion, an accelerator or a fast reactor, and seems to be more efficient than the soft one. Actinide burning needs a very long time (>30 years) of reactor operation; the Th-U cycle can extend the operation time and get deep burnup, so actinide burning with the Th-U cycle in the external fusion neutron source is the best way for both burning TRU and energy output.

In the calculation, the FFR performs very well for burning ${ }^{237} \mathrm{~Np},{ }^{239} \mathrm{Pu}$ and ${ }^{241} \mathrm{Am}$ and marginally well for burning ${ }^{240} \mathrm{Pu}$, but it fails to burn ${ }^{238} \mathrm{Pu},{ }^{241} \mathrm{Pu}$ and ${ }^{244} \mathrm{Cm}$ isotopes. Because about $90 \%$ of TRU fuel mass consists of ${ }^{239} \mathrm{Pu},{ }^{240} \mathrm{Pu},{ }^{241} \mathrm{Am}$ and ${ }^{237} \mathrm{~Np}$, the FFR appears to be successful in actinide burning. ${ }^{238} \mathrm{Pu}$ seems to very important to BHP (relative to human hazard) until 100 cooling years have passed, and ways to reduce ${ }^{238} \mathrm{Pu}$ are worthy of further study.

\section{References}

1. A. Renard et al., Actinide Recycling for Reactor Waste Mass and Radioactivity Reduction, in Proc. Fifth Annual Int'l. Conf. on High-Level Radioactive Waste Management, 1994 (Am. Nuc. Soc., La Grange Park, 1994), pp. 1682-1686.

2. B. Hyland and G.R. Dyck, Actinide burning in CANDU reactors, in Global 2007 Conference on Advanced Nuclear Fuels Cycles and Systems (Boise, Idaho, 2007). 
3. B. Hyland et al., Transmutation of americium in light and heavy water reactors, in Proceedings of Global 2009 (Paris, 2009).

4. C.W. Forsberg and E. Greenspan, Molten Salt Reactors (MSRs): Coupling Spent Fuel Processing and Actinide Burning, in Advances in Nuclear Fuel Management III (ANFM 2003), (Hilton Head Island, 2003).

5. P. Hejzlar, M.J. Driscoll and M.S. Kazimi, Conceptual Reactor Physics Design of a LeadBismuth-cooled Critical Actinide Burner, Topical Report MIT-ANP-TR-069 (Massachusetts Institute of Technology, Dept. of Nuclear Eng., January, 2000).

6. B.B. Cipiti et al., Fusion transmutation of waste: design and Analysis of the in-zinerator Concept, Sandia report, SAND2006-6590 (Nov. 2006). 